\title{
Demands of pregnant employees towards clinical hospital centre administration
}

\author{
Hrvoje Lalić* \\ Health Centre Rijeka, Croatia
}

Received: March 3, 2019

DOI: $10.5430 /$ jha.v8n3p46

\author{
Accepted: May 13, 2019 \\ Online Published: May 22, 2019 \\ URL: https://doi.org/10.5430/jha.v8n3p46
}

\begin{abstract}
The healthcare sector in Croatia is predominantly composed of female employees across all levels. The Clinical Hospital Centre Rijeka with 3,000 employees is no exception. The Republic of Croatia is populated by a little over 4 million inhabitants and the numbers have been in a constant decline due to multiple factors, which include aging of the population and economic migrations. These two factors significantly impact the healthcare workforce and specifically medical personnel. In the era where there are less and less new marriages and newborns, the government struggles for every child and thus offers families exceptional parental benefits. For hospitals, which are mainly staffed by women, confronting the government politics that seek to advantage the pregnant employees' presents a problem and a significant financial burden. This is due to the fact that they are entitled to the full salary whilst staying at home from the very early stage of pregnancy. Theoretically, if the hospital management offered their pregnant employees all the benefits that law provides, the hospital would soon be left without sufficient number of nurses and particularly doctors, because they would very soon after becoming pregnant simply stop working. The Health and Safety Law states that if the employer in health care, i.e. in a hospital, cannot provide a safe working environment for their pregnant employees, prior to their regular maternity leave financed by the state, they are not obliged to work and are entitled to a full salary, which is financed by the hospital itself. A female medical doctor found the article in the law that allows a full salary when she stopped working. She claimed such a benefit at the very beginning of her otherwise regular pregnancy and soon after that other cases followed. The occupational medicine doctors, after this first claim were soon put in a position to issue another 15 certificates of work incapacity to women at the very early stages of their pregnancy. That seriously exhausts modest hospital funds due to the prevalence of female employees. Thus, in the Clinical Hospital Centre, urgent action is needed to prevent future "epidemic" compensation claims. Occupational Medicine in cooperation with the Health and Safety Service together with the hospital management found a solution to the problem to the mutual benefit of all the parties involved. The personalized work post for pregnant medical staff was to be created, one without the exposure to biotic agents. Pregnant employees can hold administrative or educational work places, and should they feel unwell, they can always take regular sick leave, organised by their family doctor or gynaecologist and paid for by the Croatian Institute for Health Insurance. Pregnancy is not an illness; women can work and help the work of the hospital which is extraordinarily important especially when medical doctors are concerned for their absence is very expensive and hard to compensate. Although the sick leave pays less than the regular salary, the compromise is necessary to maintain the hospital solvent.
\end{abstract}

Key Words: Pregnant employees, Hospital administration, Occupational medicine

\section{INTRODUCTION}

In the Republic of Croatia there is a lack of hospital staff, as it is the case in most European countries, as well as in those developed but especially undeveloped countries all over the world. Republic of Croatia has approximately 4,200,000 inhabitants and 14,000 medical doctors, out of which there

*Correspondence: Hrvoje Lalić; Email: hlalic@inet.hr; Address: Health Centre Rijeka, Croatia. 
are 9,500 female medical doctors and 4,500 male medical doctors. The Clinical Hospital Centre Rijeka employs 3,000 persons, mostly medical staff and mostly female. That "feminization" can also be seen at the medical faculties where male students have become rare. The pregnant employees early, mostly at the very beginning of their pregnancy, tend to go on sick leave. Those employees must be substituted by the others from the same establishment, who become psychically and physically overburdened. The evidence of interventions targeting sickness absence among pregnant women in health settings is sparse. ${ }^{[1]}$

The Health and Safety Law states that pregnant employees cannot be exposed to potentially hazardous biological agents. ${ }^{[2]}$ More precise Law came through some time later, but in the same year, 2014. The Risk Assessment Law states that the employer is responsible to ensure that the pregnant employee has a safe work post and should such conditions not be met, the employer is obliged to send the pregnant employee home and pay her full salary until the time for regular maternity leave. ${ }^{[3]}$ Hospital management in cooperation with OM and Safety at Work decided to improve safety conditions on work posts in order to keep the pregnant employees present at work as long as possible.

Until recently, the pregnant women went on a sick leave according to and up to their own discretion, i.e. the recommendation of their gynaecologist and depending on the state of their health and pregnancy. Such a sick leave was obtained as pregnancy complications and in accordance with one's general practitioner or the gynaecologist on the level of primary care and it had been practised for many decades.

Approximately one month ago, a young female medical doctor who was in the process of completing her specialization at the Clinical Hospital Centre Rijeka, found a legal loophole and came to the Occupational medicine surgery claiming Certificate of contemporary working incapacity for her work at the Department of Gynaecology, because there she can be exposed to potentially hazardous biological agents. She arrived at the Department of OM sent by the Health and Safety at Work unit. According to and strictly observing the law, OM doctor was obliged to issue her colleague a certificate that confirmed her not capable of work during her otherwise normal pregnancy.

The same day the legal loophole knowledge had been shared among the hospital medical staff and within one month there were other 15 pregnant women, some nurses and some doctors, who applied and received the temporary incapacity for work certificate. In other words, they found a way to receive full salary on the hospital's expense whilst staying at home and not claiming the state sick benefit which pays con-

Published by Sciedu Press siderably less. All this resulted in the hospital's financial crisis and endangered its solvency. The alarm bells went on and the management set up an emergency meeting together with the OM specialists to solve the problematic situation to everybody's satisfaction, taking into consideration all the parties and particularly the employees' health. The personalization of every single work place had been arranged for every pregnant employee, with the intent to keep them at work as long as possible until their regular maternity leave. In the case of complications they could always take a sick leave through the Croatian Institute of Health Insurance and not at the expense of the hospital centre.

\section{EXAMINEES AND METHODS}

The examined were 15 pregnant employees of the Clinical Hospital Centre Rijeka, Croatia, who claimed for paid absence from work.

They claimed the certificate of working incapacity during their pregnancies. After a female medical doctor found the article in the law that allows the paid absence from work and received the Certificate of incapacity, the news quickly spread throughout the whole Clinical Hospital Centre. Another fifteen pregnant employees came to the occupational medicine stimulated by example of the mentioned doctor and also asked for such certificates.

The occupational medicine in cooperation with hospital management was forced to review every single work post of their pregnant employees and analyse it for potential biological or chemical hazards. This way the pregnant employees would be kept safe at their work places until their regular maternity leave. Introducing the personalized work post without the exposure to biotic agents for pregnant medical staff, prevents further sick leaves. In the hospital with 3,000 mostly female employees, on the basis of 15 employees who immediately claimed incapacity it is to be expected that every new pregnant woman would ask for the same. Therefore, in order to save the hospital budget, the following method, which prevents future premature sick-leaves is applied: every new pregnant employee is directed to the Health and Safety department, a personalized work place is created and separately approved by the occupational medicine specialist.

\section{RESUlTS}

"The Epidemic" of claimants for this certificate took place after the first certificate was issued. News about this legal loophole spread through the entire hospital very quickly, resulting in the arrival of 15 new pregnant employees at the Department of Occupational Medicine, all of whom were only in their first months of pregnancy. 
It was clear from the very beginning that this presents a very heavy burden on the modest hospital budget and that something must be done for both the employees and the hospital. The OM specialists expected a call for the meeting to solve this problem together with the hospital management. The result is personalization of workplace on the basis of the risk assessment of every new work place created for every new pregnant employee with the aim to keep them at work as long as possible.

\section{Discussion}

Pregnant women experience physiological and immunological changes that increase the risk or severity of certain pulmonary infections. ${ }^{[4]}$ One should also not forget tuberculosis (TB), which is still present in population nowadays. ${ }^{[5]}$ It is the time of recession; unemployment is relatively high and poverty is a good base for spreading contagious diseases, especially in population infected by HIV and other immunodeficiency diseases. Some of viruses like cytomegalovirus (CMV) can be transmitted to foetus causing hearing loss and neurological changes. ${ }^{[6]}$

Ionizing radiation zone is restricted area for all pregnant employees, so there are no pregnant employees in any hospital departments where exposures are possible. Ionizing radiation can cause carcinogen and mutagen effects. ${ }^{[7]}$ One comes across ionizing radiation at departments of radiology, oncology, nuclear medicine, as well as at surgical and trauma departments, internal medicine, emergency medicine, in short, nowadays there are almost no departments where the X - Ray apparatuses are not used. Changes caused by ionizing radiation are multiple, especially acting mutagenic, and they had been described and proven in humans as well as in experimental animals. ${ }^{[8]}$

The same applies for dangerous chemicals. Anaesthetic fumes at departments of surgery and anaesthesiology are risk factors that influence fertility, central nervous system and are proven carcinogens. ${ }^{[9]}$

Health workers are sometimes exposed to the heavy physical work and that applies more to the nurses than female physicians. Nurses often lift and manipulate immobile or partially immobile patients and that is a heavy physical work. Lifting heavy weight can cause spontaneous abortion. ${ }^{[10]}$

As far as shift work is concerned, which is frequent in hospitals, the studied do not show a significant influence on fertility. ${ }^{[11]}$

Thus, as already mentioned above, it can be concluded that the pregnant employees are forbidden to work in ionizing radiation zones, work with dangerous chemicals, cytostatics and, anaesthetics. They are forbidden direct contact with wounds, blood, infective patients, needles for injections and infusions.

However, at the Clinical Hospital Centre there is a sufficient number of work posts where there are no exposures to such dangers. In the other hand, part of a problem is also the fact that such working posts are not defined by laws and regulations.

It is important to accentuate that pregnancy is not an illness and during pregnancy it is possible to conduct light types of work for quite a while. Normally, this applies only to regular, not complicated pregnancy, where the bed rest is ordered by gynaecologist from the very beginning. Also, it is much easier to solve the problem of pregnant nurses than pregnant medical doctors.

Nurses mostly have secondary school level of education, thus it is easier to employ them in administration.

It is more complicated to find an alternative work for medical doctors who have higher education and cannot do low rank jobs and are expensive to replace. However, that does not mean that they cannot do anything else. They could write anamnesis, hospital discharge summaries, or mentor students and younger colleagues at specializations. All the above can be done at the adequate departments and with no exposure to the risk of their health.

Female medical doctors are very revolted with their employer's decision that it is compulsory for them to stay at work during pregnancy and threaten with protests via human rights associations and associations for women's rights which often use TV and other media to put across their views. OM specialist with every new case of pregnancy also has to deal with unpleasant commentaries from pregnant employee when they find out they have to stay at work.

However, it is clear that pregnant employees go out from their houses, they go to grocery shops, supermarkets, they travel by bus or train and they are in contact with other people on the daily basis. Many of them live in urban areas with heavy traffic and are exposed to exhaust fumes from motor vehicles that are proven to influence foetal growth and gestational duration. ${ }^{[12]}$

In conclusion, conducting the personalized medicine the agreement has been reached between the occupational medicine specialists and the hospital management that risk assessment for every single work post for new pregnant employee is necessary. Thus, pregnant employees would be kept at work as long as possible until their regular maternity leave, which is 45 days prior to giving birth. This way the 
hospital would save considerable funds, and if need be, every pregnant employee can take the regular sick leave trough primary care or their gynaecologist and at the expense of the Croatian Institute for Health Insurance.

Female medical doctors should be aware of the difficult circumstances of the health system in general and that they should help in supporting the system for as long as possible before the maternal leave. It is important to point out that should they under the circumstances be temporarily placed to the lower ranking position, they are protected by the Health and Safety law and their salary remains on the level of their regular work.

There is a general opinion that the young female doctors on specialization, which make a great part of the above mentioned pregnant employees, should contribute and pay back to the society that provided for their education and position, by showing willingness to work and be active and not additionally exhaust modest hospital funds. The legislator fully respects the vulnerability of pregnancy and searches secure working place with contraindications such as biological and chemical exposures, $\mathrm{X}$ - Ray exposures and cytostatics. The young female doctors know this very well, so understanding from their side it is to be expected.

\section{Conclusion}

With all due respect to the gender equality, females have their reproductive role that is active especially at younger age. The longer stay at work during pregnancy can be achieved in cooperation between the female employees, OM and the Health and Safety department.

Occupational medicine has proved its important role in this new situation, helping the hospital management to maintain solvency. Almost all medical branches care only for the patient - Occupational Medicine here differs - it also aims to look after the employer, the firm, but never neglecting the patient and their rights within the law.

\section{CONFLicts OF INTEREST Disclosure}

The author declares they have no conflicts of interest.

\section{REFERENCES}

[1] Pedersen P, Lalbriola M, Nielsen CV, et al. Systematic review of interventions targeting sickness absence among pregnant women in healthcare settings and workplaces. BMJ Open. 2018; 8(10): e024032. PMid:30366917. https://doi.org/10.1136/bmjope n-2018-024032

[2] People's Gazette. The Law about the health protection. 71; 2014.

[3] People's Gazette. The Law about the risk assessment. 112; 2014.

[4] Mathad JS, Gupta A. Pulmonary infections in pregnancy. Semin Resp Crit Care Med. 2017; 38(2): 174-184. PMid:28561248. https: //doi.org/10.1055/s-0037-1602375

[5] Bates M, Ahmed Y, Kapata N, et al. Int J Infect Dis. 2015; 32: 124-7. PMid:25809768. https://doi.org/10.1016/j.ijid. 2014.12 .014

[6] Cannon MJ, Schmid DS, Hyde TB. Review of cytomegalovirus seroprevalence and demographic characteristics associated with infection. Reviews in Medical Virology. 2010; 20(4): 202-13. PMid:20564615. https://doi.org/10.1002/rmv.655

[7] Lalić $\mathrm{H}$. Cytogenetic monitoring of medical staff professionally exposed to Gamma and X radiation. Neoplasma. 2005; 52(4): 307-13.
[8] Tomasova L, Smajda B, Sevc J. Effects of prenatal irradiation on behaviour and hippocampal neurogenesis in adult rats. Acta Physiol Hung. 2012; 99(2): 126-32. PMid:22849836. https://doi .org/ 10.1556/APhysiol.99.2012.2.5

[9] Boeckelmann I, Sammio S, Meyer F. Work strain by anaesthetic gas and surgical smoke due to tissue coagulation as well as safety measures in surgical operating rooms - what the surgeon needs to know. Zentralbl Chir. 2013; 138(1): 94-103. https ://doi .org/10 $.1055 / \mathrm{s}-0032-1328179$

[10] Banerjee B, Dey TK, Chatterjee P. Work related physical exertion and spontaneous abortion. Indian J Public Health. 2005; 49(4): 248-9.

[11] Zhu JL, Hjollund NH, Boggild H, et al. Shift work and subfecundity; a casual link or an artefact? Occup Environ Med. 2003; 60(9): E12. PMid:12937208. https://doi.org/10.1136/oem.60.9.e12

[12] Amegah AK, Jaakkola JJ. Work as street wendor, associated trafficrelated air pollution exposures and risk of adverse pregnancy outcomes in Accra, Ghana. Int J Environ Health. 2014; 217(2-3): 354-62. PMid:23973506. https://doi.org/10.1016/j.ijheh.2013.0 7.010 